\title{
Polyhydramnios: ultrasonographic detection, associated risk factors and perinatal outcome
}

\author{
Prerna Gupta, Sangeeta Sen \\ Correspondence: Dr. Prerna Gupta, Junior resident, Department of Obstetrics and \\ Gynaecology, Court Chouraha, RNT Medical College and Hospital, Udaipur, Rajasthan, \\ India; Email-prernagupta1919@gmail.com
}

Distributed under Creative Commons Attribution-Share Alike 4.0 International.

\begin{abstract}
$\underline{\text { ABSTRACT }}$
Objectives: Detection of polyhydramnios by ultrasonography and studying its associated risk factors and following up for its perinatal outcome were the objectives of this study. Methods: It was an observational study in which 70 antenatal cases of polyhydramnios from 20-42 weeks of gestation were taken into consideration, irrespective of age and parity. Results: Out of total 70 patients in the study, $42.8 \%$ were diagnosed at gestational age of 33-37 weeks. Forty (57.14\%) cases were having mild polyhydramnios. Thirty eight $(54.28 \%)$ cases had no associated risk factors. In rest of cases congenital malformation $24.27 \%$ and diabetes $7.14 \%$ were associated as the risk factors. Forty (57.1\%) pregnancies had no complication but $10 \%$ developed preterm labor. Thirty six $(51.42 \%)$ cases had normal vaginal delivery and $31.42 \%$ had caesarean section. Fifty three (75.71\%) of newborns were alive but $17.14 \%$ had neonatal death. Conclusion: Most cases were diagnosed after 28 weeks and most had idiopathic and mild polyhydramnios. Diabetes and congenital malformation were the most frequent associated risk factors. Preterm labor represented the most frequent complication. Caesarean section as a mode of delivery was higher.
\end{abstract}

Keywords: Amniotic fluid, AFI, polyhydramnios, ultrasonography.

Polyhydramnios is a condition in which there is excess of liquor amnii surrounding the foetus. Arbitrarily more than $2 \mathrm{~L}$ of amniotic fluid is considered excessive and termed as polyhydramnios. It is identified in approximately $1 \%$ of pregnancies [1]. Polyhydramnios can be idiopathic or it can be associated with several aetiological factors [2-4]. The factors can be foetal, placental or maternal. The majority of cases are mild or moderate in severity and are idiopathic. When it is severe an underlying foetal cause is likely. The clinical diagnosis of polyhydramnios should always be confirmed by ultrasonography. Methods used are the measurement of the single deepest pocket and the measurement of amniotic fluid index. Polyhydramnios is associated with a number of maternal (Respiratory distress, Preeclampsia, Abruption placentae, Placenta accrete, Body weight gain $\geq 20 \mathrm{~kg}$ during pregnancy, Post partum haemorrhage) and foetal (Preterm delivery, Premature rupture of membranes, Umbilical cord prolapse, Low birth weight, Large for gestational age baby, Intra uterine foetal death, Meconium stained amniotic

Received: $9^{\text {th }}$ May 2016. Accepted: $17^{\text {th }}$ July 2016 .

Gupta P, Sen S. Polyhydramnios: ultrasonographic detection, associated risk factors and perinatal outcome. The New Indian Journal of OBGYN. 2017; 3(2): 100-4 
fluid)complications [5]. Early detection of polyhydramnios and its appropriate antenatal management can help the clinician prevent the foreseen complications related to perinatal outcome [6-9]. So, in this observational study design, we planned to identify the risk factors associated with polyhydramnios and followed up the cases to relate it to the perinatal outcome.

\section{Methods}

In this study, 70 antenatal cases after 20 weeks of gestation were taken into consideration after a detailed history and examination.

Inclusion criteria:

- All cases of polyhydramnios, irrespective of age and parity, either singleton/multiple pregnancies having AFI $\geq 25 \mathrm{cms}$ or maximum vertical pocket $\geq 8 \mathrm{cms}$.

- Gestational age 20-42 weeks.

Exclusion criteria:

- Pregnancies associated with overdistended abdomen other than polyhydramnios.

- First trimester pregnancies

The cases suspected to have polyhydramnios clinically were subjected to ultrasonographic assessment of their amniotic fluid index. Diagnosis of polyhydramnios was confirmed if patient had AFI $\geq 25$ $\mathrm{cms}$ or maximum vertical pocket $\geq 8 \mathrm{cms}$ [10]. The subjects who had polyhydramnios were carefully followed for associated risk factors and perinatal outcome associated with the condition was observed.

\section{Results}

When studied according to gestational age of

\begin{tabular}{|l|l|}
\hline $\begin{array}{l}\text { Table 1: Gestational age in } \\
\text { weeks at diagnosis }\end{array}$ \\
\hline $\begin{array}{l}\text { Gestational } \\
\text { age (wks) }\end{array}$ & $\begin{array}{l}\text { No. of Patients } \\
\text { (\%) }\end{array}$ \\
\hline Less than 28 & $20(28.57 \%)$ \\
\hline $28-32$ & $15(21.42 \%)$ \\
\hline $33-37$ & $30(42.85 \%)$ \\
\hline $38-42$ & $5(7.14 \%)$ \\
\hline
\end{tabular}
diagnosis, it was found that, 20 $(28.57 \%)$ of them were diagnosed at gestational age < 28 weeks, 15 $(21.42 \%) \quad$ were diagnosed at gestational age

\begin{tabular}{|l|l|l|l|}
\hline \multicolumn{4}{|l|}{ Table 2: Amniotic fluid volume } \\
\hline Categories & $\begin{array}{l}\text { AFI } \\
\text { (Amniotic } \\
\text { fluid index) }\end{array}$ & $\begin{array}{l}\text { Maximum } \\
\text { vertical } \\
\text { pocket } \\
\text { depth }\end{array}$ & $\begin{array}{l}\text { Number } \\
(\%)\end{array}$ \\
\hline Mild & $25-30 \mathrm{cms}$ & $8-11 \mathrm{cms}$ & $40(57.14 \%)$ \\
\hline Moderate & $30.1-35 \mathrm{cms}$ & $12-15 \mathrm{cms}$ & $25(35.71 \%)$ \\
\hline Severe & $\geq 35.1 \mathrm{cms}$ & $\geq 16 \mathrm{cms}$ & $5(7.14 \%)$ \\
\hline
\end{tabular}

between 28-32 weeks, 30(42.85\%) between 33-37 weeks and 5(7.14\%) were diagnosed between $38-42$ weeks (table 1).

Using the ultrasound to confirm polyhydramnios, 40 (57.14\%) of the cases had a deepest pool of the amniotic fluid volume in the range of $8-11 \mathrm{cms}$ and

\begin{tabular}{|c|c|}
\hline \multicolumn{2}{|c|}{$\begin{array}{l}\text { Table 3: Screening for associated risk factors in } \\
\text { the current pregnancy }\end{array}$} \\
\hline Risk factors & $\begin{array}{l}\text { Number of } \\
\text { patients }(\%)\end{array}$ \\
\hline No Risk Factors & $38(54.28 \%)$ \\
\hline \multicolumn{2}{|l|}{ Maternal factors } \\
\hline Diabetes mellitus & $5(7.14 \%)$ \\
\hline Intrauterine infections & $1(1.42 \%)$ \\
\hline Multiple Pregnancies & $5(7.14 \%)$ \\
\hline \multicolumn{2}{|l|}{ Foetal factors } \\
\hline $\begin{array}{ll}\text { Rhesus } & \text { Isoimmunisation } \\
\text { Complicated } & \text { with hydrops } \\
\text { fetalis } & \end{array}$ & $4(5.71 \%)$ \\
\hline Neural tube defects & $12(17.14 \%)$ \\
\hline Gastrointestinal defects & $3(4.28 \%)$ \\
\hline Cleft lip \& palate & $2(2.85 \%)$ \\
\hline
\end{tabular}

AFI in range of $25-30 \mathrm{cms}, 25(35.71 \%)$ had deepest pool in the range of $12-15 \mathrm{~cm}$ and AFI $30.1-35 \mathrm{cms}$, and in $5(7.14 \%)$ the deepest pool was more than $\geq 16$ $\mathrm{cm}$ with $\mathrm{AFI} \geq 35.1 \mathrm{cms}$ (table 2 ).

It was found that $38(54.28 \%)$ of the cases had no related risk factors, while 32 (45.72\%) of them had risk factors. These risk factors were maternal - diabetes 
mellitus in 5(7.14\%), 5(7.14\%) cases had multiple pregnancies and $1(1.42 \%)$ had intrauterine infections and foetal - rhesus isoimmunisation complicated with hydrops fetalis in 4(5.71\%), neural tube defects in 12 $(17.14 \%)$, gastrointestinal defects in $3(4.28 \%)$ and 2(2.85\%) had cleft lip and palate (table 3 ).

Regarding the complications arising during the current pregnancy, 7 (10\%) developed preterm labour, $3(4.28 \%)$ suffered from acute abdominal pain, $5(7.14 \%)$ had premature rupture of membranes and

\begin{tabular}{|l|l|}
\hline $\begin{array}{l}\text { Table 4: Complications arising during the } \\
\text { current pregnancies }\end{array}$ \\
\hline Complications & $\begin{array}{l}\text { No. of Patients } \\
(\%)\end{array}$ \\
\hline Developed preterm labour & $7(10 \%)$ \\
\hline Acute abdominal pain & $3(4.28 \%)$ \\
\hline Premature rupture of membranes & $5(7.14 \%)$ \\
\hline Intrauterine fetal deaths & $3(4.28 \%)$ \\
\hline Pre-eclampsia & $4(5.71 \%)$ \\
\hline Placental abruption & $3(4.28 \%)$ \\
\hline Post partum haemorrhage & $3(4.28 \%)$ \\
\hline Body weight gain > 20 kgs. & $2(2.85 \%)$ \\
\hline No complication & $40(57.1 \%)$ \\
\hline
\end{tabular}

$3(4.28 \%)$ ended with intrauterine fetal deaths, 4(5.71\%) had pre-eclampsia, $3(4.28 \%)$ had placental abruption, $3(4.28 \%)$ had post partum haemorrhage, $2(2.85 \%)$ had body weight gain $>20 \mathrm{Kgs}$, and the others $40(57.1 \%)$ had no complication.(table 4)

Regarding the gestational age at delivery, 5(7.14\%) delivered at gestational age less than 28 weeks, 12(17.14\%) between 28-32 weeks, 15 (21.42\%) between 33-37 weeks and 38(54.28\%) delivered at gestational age between $38-42$ weeks. In relation to the mode of delivery, $36(51.42 \%)$ delivered spontaneous vaginal delivery, $12(17.14 \%)$ had induced labor, $16(22.85 \%)$ were delivered by emergency caesarean section and $6(8.57 \%)$ by elective Caesarean section for various obstetric indications.

When compared for perinatal outcome, 53(75.7\%) of the newborns were alive, $2(2.85 \%)$ were fresh stillbirths, 3(4.28\%) were intrauterine deaths and
$12(17.14 \%)$ ended with early neonatal deaths. Regarding the birth weight, out of 70 cases, 15 $(21.43 \%)$ newborns weighed less than $2.5 \mathrm{Kgs}, 50$ (71.42\%) ranged between $2.5-4 \mathrm{Kgs}$ and $5(7.14 \%)$ weighed more than $4 \mathrm{Kgs}$. Fifty six $(80 \%)$ of the newborns had no apparent congenital malformations whereas in $14(20 \%)$ of them, apparent congenital malformation were observed. The distribution of the apparent congenital malformation were as follows: anencephaly in $10(71.42 \%)$ of cases, $2(14.28 \%)$ had cleft lip and palate, and 2(14.28\%) had encephalocele .

\section{Discussion}

In relation to gestational age at diagnosis in weeks most of the patients $(71.4 \%)$ were diagnosed after 28 weeks and only $(28.5 \%)$ were diagnosed before that, this indicates that polyhydramnios accumulates gradually and only noticed after 30 weeks while in few cases polyhydramnios accumulates quickly and diagnosed earlier. Forty (57.14\%) of the cases had mild polyhydramnios, $35.71 \%$ had moderate and in $7.14 \%$ it was severe polyhydramnios. These results are similar to the study done by Jacoby and Chales [11] where $59.3 \%$ were mild, $35.3 \%$ moderate and $6.4 \%$ severe out of 156 cases. Hills et. al. [1] found mild polyhydramnios in $79 \%$ cases, moderate in $16 \%$, and severe in $5 \%$ cases, out of total 85 cases. This can be explained by the fact that, most of the cases of polyhydramnios are mild.

It is observed that $54.28 \%$ of the cases had no related risk factors in the current pregnancy, while $45.72 \%$ of them had risk factors; $7.14 \%$ of the total cases were diabetic, $(24.2 \%)$ had structural congenital malformations, these results are similar to that from the study done in Switzerland in 1993 by Golan A et al [5].

In this study, $57.1 \%$ of the patients had no complications arising during the current pregnancy and this can be explained by that most of the cases were idiopathic and mild. Preterm labour represented the most frequent complication (10\%), 4.28\% suffered from acute abdominal pain, $7.14 \%$ had premature rupture of membranes and $4.28 \%$ ended with intrauterine fetal deaths, $5.71 \%$ had pre-eclampsia, $4.28 \%$ had placental abruption, $4.28 \%$ had post partum 
haemorrhage, $2.85 \%$ had body weight gain $>20 \mathrm{Kgs}$. Jaccoby and Charles [11], in their study detected 156 cases of polyhydramnios, various maternal and fetal complications were diabetes $26.3 \%$, preterm labor $25.6 \%$, pre-eclapmsia $14 \%$, premature rupture of membrane $19.3 \%$, breech presentation $11 \%$, anemia $9.6 \%$, postpartum haemorrhage $6.4 \%, \quad \mathrm{Rh}$ isoimmunisation $3.8 \%$, cord prolapse $2.5 \%$ and antepartum haemorrhage $1.2 \%$. Hills et al. [1] detected 102 cases of mild-severe polyhydramnios, there were $21.6 \%$ cases of preterm labor, $14.7 \%$ of twin pregnancy and $1 \%$ cases of Rh-isoimmunisation. It is clear that preterm labor is a major complication of polyhydramnios and is an important cause of increased neonatal morbidity and mortality. Results of present study are in close association with above studies.

In present study, $7.14 \%$ were delivered at gestational age of less than 28 weeks, $17.14 \%$ between 28-32 weeks, $21.42 \%$ between 33-37 weeks and $54.28 \%$ delivered at gestational age between $38-42$ weeks. This is similar to the study done by Taskin et al. [12], where the gestational age at the time of delivery ranged from 24 to 41 weeks, and the mean gestational age in the groups were $38.4 \pm 1.9$. This can be explained as some cases had preterm delivery, which was the most frequent complication, and some patients had induction of labor prematurely because of the presence of congenital malformations.

In relation to the mode of delivery $31.4 \%$ of patients delivered by caesarean section and this high rate of caesarean section could be explained by the fetal macrosomia, and complications such as footling breech, cord prolapse, abruptio placentae, as reported in study from United States done by Sohaey R et al. in 1997 [13].

In this study, $75.7 \%$ of the newborns were alive, $2.85 \%$ were fresh stillbirths, $4.28 \%$ were intrauterine deaths and $17.14 \%$ ended with early neonatal deaths. This can be explained by the fact that most cases of polyhydramnios were mild and idiopathic. In our study $7.14 \%$ were stillbirths and intrauterine deaths. The early neonatal deaths were found to be $17.14 \%$ and this confirmed the high association between polyhydramnios and perinatal mortality. The high perinatal mortality can be explained by increased incidence of congenital malformations and prematurity in the newborns.

In this study, $7.14 \%$ of newborns had birth weight more than $4 \mathrm{Kgs}$, this can be explained by the association between macrosomia and polyhydramnios and gestational diabetes mellitus. Most of the newborns (80\%) had no apparent congenital malformation and this is because most of the patients had no risk factors in their current pregnancy. Twenty percent newborns with congenital malformations, neural tube defect accounted for $85.7 \%$ cases with anencephaly being the commonest. This incidence was comparable to similar results in the studies conducted by Romero Gutierrez (24\%), Ben-Chetrit A (21.8\%), Lyndon M Hill (20\%), R William Quinlan (18\%) and Desmedt (17.8\%) [1418]. However the incidence of congenital anomalies were lower in the studies conducted by Shabnam (2.8\%), Kaukab Tashfeen (8.1\%), Joseph R Biggo (8.4\%), Dashe (11\%) and Lazebnik (14.5\%) [19-23].

\section{Conclusion}

In this study, most of the cases had been diagnosed after the gestational age of 28 weeks and most of them had idiopathic and mild polyhydramnios. Diabetes and congenital malformation were the frequent associated risk factors of polyhydramnios. Preterm labour represented the dominant complication of polyhydramnios. Caesarean section as a mode of delivery was found to be higher in cases of polyhydramnios than the international rate. There is a high incidence of fetal macrosomia in cases of polyhydramnios even in non diabetic mothers. Neural tube defect and intestinal obstruction are the commonest congenital malformation associated with polyhydramnios. Polyhydramnios is associated with high perinatal mortality and morbidity rate.

\section{Conflict of interest: None. Disclaimer: Nil.}

\section{References}

1. Hill LM, Breckle R, Thomas ML, et al.

Polyhydramnios: ultrasonically detected prevalence and neonatal outcome. Obstet Gynecol. 1987; 69: 21 
2. Phelan JP, Martin GI. Polyhydramnios: fetal and neonatal implications. Clin Perinatol. 1989; 16: 987.

3. Ben-Chetrit A, Hochner-Celnikier D, Ron M, et al. Hydramnios in the third trimester of pregnancy: a change in the distribution of accompanying fetal anomalies as a result of early ultrasonographic prenatal diagnosis. Am J Obstet Gynecol.1990; 162: 1344

4. Stoll CG, Alembik Y, Dott B. Study of 156 cases of polyhydramnios and congenital malformations in a series of 118,265 consecutive births. Am J Obstet Gynecol. 1991; 165: 586.

5. Golan A, Wolman I, Sagi J, et al. Persistence of polyhydramnios during pregnancy - its significance and correlation with maternal and fetal complications. Gynecol Obstet Invest. 1994; 37: 18.

6. Magann EF, Chauhan SP, Doherty DA, et al. A review of idiopathic hydramnios and pregnancy outcomes. Obstet Gynecol Surv. 2007; 62: 795-802

7. Smith CV, Plambeck RD, Rayburn WF, et al. Relation of mild idiopathic polyhydramnios to perinatal outcome. Obstet Gynecol. 1992; 79: 387.

8. Touboul C, Boileau P, Picone O, et al. Outcome of children born out of pregnancies complicated by unexplained polyhydramnios. BJOG. 2007; 114: 489.

9. Many A, Hill LM, Lazebnik N, et al. The association between polyhydramnios and preterm delivery. Obstet Gynecol. 1995; 86: 389.

10. Nabhan AF, Abdelmoula YA. Amniotic fluid index versus single deepest vertical pocket as a screening test for preventing adverse pregnancy outcome. Cochrane Database Syst. Rev 20083CD006593

11. Jacoby HE, Charles D. Clinical condition associated with hydramnios. Am J Obstet Gynecol. 1996; 94: 910

12. Taskin S, Pabuccu EG, Kanmaz AG, Kahraman K, Kurtay G. Perinatal outcomes of idiopathic polyhydramnios. Interventional Medicine \& Applied Science. 2013; 5(1): 21-5.

13. Sickler GK, Nyberg DA, Sohaey R, Luthy DA. Polyhydramnios and fetal intrauterine growth restriction: ominous combination. J Ultrasound Med. 1997; 16: 60914.
14. Romero Gutierrez G, Fuentes Paramo H, Membrila Alfaro E, Vargas Huerta M. Ultrasonographic diagnosis of polyhydramnios and its association with congenital malformations. Ginecol Obstet Mex. 1996; 64: 1-5.

15. Ben-Chetrit A, Hochner-Celnikier D, Ron M, Yagel S. Hydramnios in the third trimester of pregnancy: a change in the distribution of accompanying fetal anomalies as a result of early ultrasonographic prenatal diagnosis. Am J Obstet Gynecol. 1990; 162(5): 1344-5.

16. Hill, Lyndon M, Breckle, R, Thomas Marion L, Fries, Joanne K. Polyhydramnios: Ultrasonically Detected Prevalence and Neonatal Outcome. Obstet Gynecol. 1987; 69: 21-5.

17. Quinlan RW, Cruz AC, Martin M. Hydramnios: ultrasound diagnosis and its impact on perinatal management and pregnancy outcome. Am J Obstet Gynecol. 1983; 145(3): 306-11

18. Beischer N, Desmedt E, Ratten G, Sheedy M. The significance of recurrent polyhydramnios. Aust NZG Obstet Gynaecol. 1993; 33: 25-30.

19. Shabnam MM, Syed S, Rizvi G. Polyhydramnios: Risk factors and outcome. Saudi Med J. 2008; 29: 256-60.

20. Tashfeen K, Hamdi IM. Polyhydramnios as a Predictor of Adverse Pregnancy Outcomes Sultan Qaboos Univ Med J. 2013; 13(1): 57-62.

21. Biggo JR Jr, Wenstrom KD, Dubard MB, Cliver SP. Hydramnios prediction of adverse perinatal outcome. Obstet Gynecol. 1999; 94: 773-7.

22. Dashe JS, McIntire DD, Ramus RM, Santos-Ramos R, Twickler DM. Hydramnios: Anomaly prevalence and sonographic detection. Obstet Gynecol. 2002; 100: 134-9.

23. Lazebnik N, Hill LM, Guzick D, Martin JG, Many A. Severity of polyhydramnios does not affect the prevalence of large-for-gestational-age newborn infants. J Ultrasound Med 1996; 15: 385-8.

Prerna Gupta ${ }^{1}$, Sangeeta Sen ${ }^{2}$

${ }^{1}$ Junior resident, Department of Obstetrics and Gynaecology RNT Medical College and Hospital, Udaipur, Rajasthan, India. ${ }^{2}$ Professor, Department of Obstetrics and Gynaecology, RNT Medical College and Hospital, Udaipur, Rajasthan, India. 